\title{
Fever treatment with a catheter-based heat exchange system in the neurointensive care unit
}

\author{
Yusuf Tunali, Eren Fatma Akcil, Ozlem Korkmaz Dilmen \\ Department of Anaesthesiology and Intensive Care, Cerrahpasa School of Medicine, \\ University of Istanbul, Istanbul, Turkey
}

Sir,

Following a neurosurgical intervention, one of the most common systemic problems encountered in the neurointensive care unit (NICU) is intractable fever [1,2]. The presence of blood either in the cerebral parenchyma, ventricles or subarachnoidal space and endogenous pyrogens as a response to neuronal injury, including surgery and infections, may cause fever. The deleterious effect of hyperthermia has been well demonstrated in various clinical conditions, including ischemic stroke, subarachnoidal hemorrhage, traumatic brain injury and following cardiopulmonary resuscitation [3-9].

Antipyretic drugs, surface cooling blankets, ice packs, nasogastric or rectal lavage and alcohol baths are wellknown traditional methods that have been used to cope with fever. However, all these modalities have pros and cons which limit their usage in the long term. Antipyretic drugs such as non-steroidal anti-inflammatory medication have side-effects which mainly cause gastrointestinal mucosal damage, renal tubular and liver dysfunctions and allergic reactions. Apart from the fact that other techniques may have limited efficiency due to skin vasoconstriction and shivering, they are also time consuming.

However, novel catheter-based heat exchange system (Alsius Coolgard 3000, Irvine, USA) has been effectively used to provide hypothermia after cardiac arrest [10] and in intensive care patients [11, 12].

Although external ventricular drainage (EVD) is lifesaving or leads staff to more closely monitor their patients' neurological status, the rate of infection related to EVD has been reported to be as high as $20 \%$ [13].

In this letter, we present three cases of fever due to EVD-related meningitis that were treated effectively with an Alsius Coolgard 3000 cooling device.

\section{CASE 1}

An 18-year-old female was admitted to the NICU due to a spontaneous idiopathic intraventricular haemorrhage. Her Glasgow Coma Score (GCS) was 12. An EVD was inserted and five days later her GCS decreased to 4. She developed respiratory failure, hypotension, tachycardia and fever $\left(41^{\circ} \mathrm{C}\right)$. She was intubated and mechanical ventilation was started. The laboratory and culture results and applied antibiotherapy are shown in Table 1. Conventional fever treatment was not able to decrease the fever to below $39^{\circ} \mathrm{C}$ over 3 days and hepatic enzyme levels increased. Therefore, we used the Alsius Coolgard 3000 cooling device. Three days later her GCS was 8 , laboratory and clinical values were normal and the heat exchange system was stopped. In addition, a percutaneous tracheotomy was opened and she was transferred to the physical rehabilitation ward.

\section{CASE 2}

A 26-year-old male was admitted to the NICU due to an arterio-venous malformation and putaminal haemorrhage with a GCS of 6 . He was urgently taken to the operating room. Following surgery, an EVD was inserted. His body temperature was alternating between hyperthermia $\left(40^{\circ} \mathrm{C}\right)$ and hypothermia $\left(32.5^{\circ} \mathrm{C}\right)$ during the early postoperative follow-up. The laboratory and culture results and applied antibiotherapy are shown in Table 1. Although the WBC count and CRP value decreased over time and repeated cultures were sterile, hypothermia and hyperthermia periods were sustained during a postoperative period of 58 days. This clinical situation led us to think that the hypothalamus was responsible for this unstable body temperature. As antipyretic drugs and external warming failed to manage hyperthermia and hypothermia, respectively, the Alsius Coolgard 3000 was used for 14 days. At the end of this period, his body 
Table 1. The laboratory and culture results and applied antibiotherapy

\begin{tabular}{|c|c|c|c|c|c|}
\hline & $\begin{array}{l}\text { Initial results of } \\
\text { WBC }\left(\mathrm{mL}^{-1}\right) \\
\text { CRP }\left(\mathrm{mg} \mathrm{dL}^{-1}\right)\end{array}$ & $\begin{array}{l}\text { Culture results of } \\
\text { ETA }\end{array}$ & $\begin{array}{l}\text { Culture results } \\
\text { of CSF }\end{array}$ & Antibiotherapy & $\begin{array}{l}\text { Repeated results of WBC }\left(\mathrm{mL}^{-1}\right) \\
\text { CRP }\left(\mathrm{mg} \mathrm{dL}^{-1}\right)\end{array}$ \\
\hline Case 1 & $\begin{array}{l}21.092 \\
80\end{array}$ & $\begin{array}{l}\text { Acinetobacter } \\
\text { baumannii }\end{array}$ & $\begin{array}{l}\text { Methicillin } \\
\text { resistant } \\
\text { Staphylococcus } \\
\text { aureus }\end{array}$ & $\begin{array}{l}\text { Linezolid }(2 \times 600 \mathrm{mg} \text { i.v. }) \\
\text { Sulbactam }- \text { cefoperazone } \\
(2 \times 1 \text { g i.v. })\end{array}$ & $\begin{array}{l}6500 \\
15\end{array}$ \\
\hline Case 2 & $\begin{array}{l}22.620 \\
87.8\end{array}$ & $\begin{array}{l}\text { Pseudomonas } \\
\text { aeuriginosa } \\
\text { Methicillin sensitive } \\
\text { Staphylococcus aureus }\end{array}$ & Enterobacter & $\begin{array}{l}\text { Meropenem }(3 \times 1 \mathrm{~g} \text { i.v. }) \\
\text { Metronidazole }(2 \times 500 \mathrm{mg} \text { i.v. }) \\
\text { Amicasine }(1 \times 20 \mathrm{mg} \text { intrathecal })\end{array}$ & $\begin{array}{l}6.099 \\
20.8\end{array}$ \\
\hline Case 3 & $\begin{array}{l}11.230 \\
264\end{array}$ & $\begin{array}{l}\text { Acinetobacter } \\
\text { baumannii }\end{array}$ & $\begin{array}{l}\text { Acinetobacter } \\
\text { baumannii }\end{array}$ & $\begin{array}{l}\text { Meropenem }(3 \times 1 \mathrm{~g} \text { i.v. }) \\
\text { Netilmisin }(2 \times 400 \mathrm{mg} \text { i.v. }) \\
\text { Netilmicin }(2 \times 3 \mathrm{mg} \text { intratecal })\end{array}$ & $\begin{array}{l}5600 \\
15.4\end{array}$ \\
\hline
\end{tabular}

WBC — white blood cell; CRP — C-reactive protein; i.v. — intravenous; ETA — endotracheal aspirate; CSF — cerebrospinal fluid

temperature became more stable and his GCS increased to $8 / 15$. He was then transferred to the physical rehabilitation ward with a tracheotomy on spontaneous breathing.

\section{CASE 3}

A 28-year-old female presented traumatic brain, thorax, pelvis and lower extremity injuries and bilateral pneumothorax. Her GCS was 6. A computerized tomography showed left frontal contusion and oedema. An EVD was inserted in order to observe intracranial pressure. Three days later her body temperature had become elevated. The laboratory and culture results and applied antibiotherapy are shown in Table 1. Despite antibiotherapy and conventional antipyretic treatment, her fever rose up to $39.3^{\circ} \mathrm{C}$, leading us to use the Alsius Coolgard 3000 cooling device for 10 days. Consequently, her WBC and CRP decreased to the baseline while the need for cooling device decreased over time. She regained consciousness and was extubated and transferred to a recovery ward on spontaneous breathing.

The effectiveness of the Coolgard 3000 cooling device regarding intractable fever due to meningitis probably caused by EVD is reported here.

This device consists of a temperature control system comprising as follows: temperature probes; an intravascular heat exchange catheter; a disposable tubing pack to connect the temperature control system; and a catheter (Fig. 1). The system circulates sterile saline in a closed loop to the balloons on the central venous catheter. The catheter has two lumens for circulation of the cooled saline and a third standard lumen (Fig. 2). The blood is cooled as it passes the membranes. The core temperature is continuously monitored via a urine catheter probe and any change results in feedback to the machine which, in turn, regulates the temperature of the saline. The operator sets the target temperature and rate of cooling.

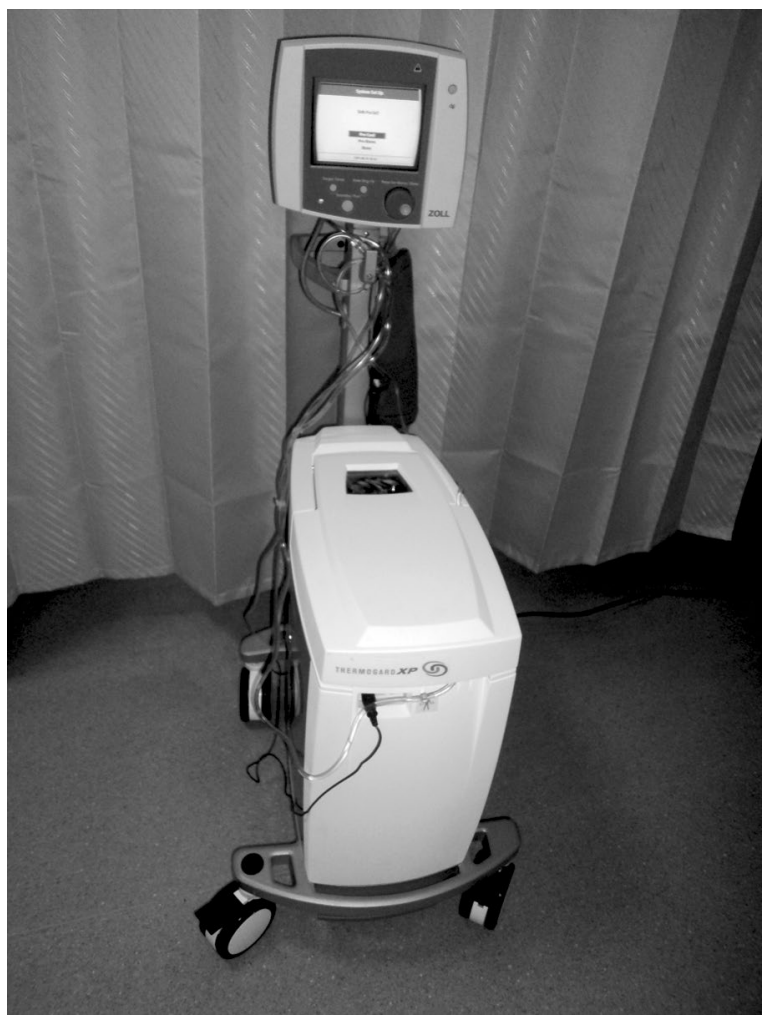

Figure 1. The Alsius Coolgard 3000 cooling device

Recent studies have shown catheter-related thrombus formation and microorganism colonization to be within acceptable limits $[14,15]$. The producer does not advise femoral catheter usage for more than 4 days or jugular and subclavian catheter usage for more than 7 days. We used only femoral route for a minimum 4 days and a maximum 14 days in our practice and did not identify any catheter-related infections. It has been advised that regular Although Doppler ultrasonography examinations should be performed 


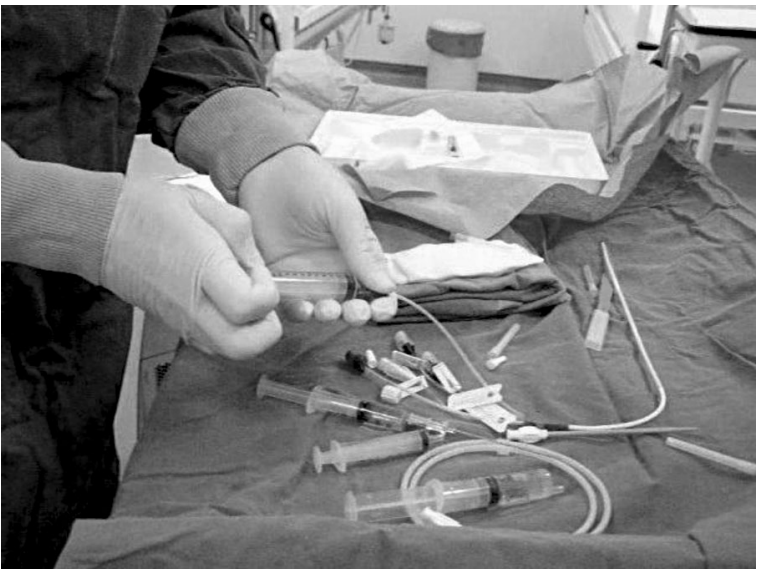

Figure 2. The temperature control catheter

to identify thrombus formation, we could not perform this regularly as it may have caused bias regarding our complication rate related to the device.

Antipyretic drugs have some gastrointestinal, renal and hepatic side effects in long-term usage. Elevated hepatic enzymes levels are common in our practice, especially when we combine antipyretics and fenitoin. The Coolgard 3000 device provides effective cooling and reduces the necessity to use antipyretic drugs.

External cooling may cause shivering and toleration may be difficult in conscious patients. Dringer et al. showed that if the tubing set is not in direct contact with the patient's skin, shivering is rare in patients using the Coolgard 3000 [11]. Indeed, we did not observe shivering in our patients while the Coolgard was being used.

Based on the cases reported here, we should acknowledge that one disadvantage of the device in hand is that as the cooling device catheter has only one extra lumen, another IV route was required for drug and fluid administration.

In conclusion, the limited experience from our patient group reported here confirms that the Coolgard 3000 cooling device is both easy to manage and provides an effective modality of treatment in patients with intractable hyperthermia.

\section{ACKNOWLEDGEMENTS}

1. The authors would like to thank Taner Tanriverdi, MD for contributions to the manuscript.

2. Source of funding - none.

3. Conflict of interests - none.

\section{References:}

1. Diringer MN, Reaven NL, Funk SE, Uman GC: Elevated body temperature independently contributes to increased length of stay in neurologic intensive care unit patients. Crit Care Med 2004; 32: 1489-1495.

2. Kilpatrick MM, Lowry DW, Firlik AD, Yonas H, Marion DW: Hyperthermia in the neurosurgical intensive care unit. Neurosurgery 2000; 47: 850-855; discussion 855-856.

3. Bernard SA, Mac CJB, Buist M: Experience with prolonged induced hypothermia in severe head injury. Crit Care 1999; 3: 167-172.

4. Oliveira-Filho J, Ezzeddine MA, Segal AZ et al.: Fever in subarachnoid hemorrhage: relationship to vasospasm and outcome. Neurology 2001; 56: 1299-1304.

5. Reith J, Jorgensen HS, Pedersen PM at al.: Body temperature in acute stroke: relation to stroke severity, infarct size, mortality, and outcome. Lancet 1996; 347: 422-425.

6. SchwabS, SchwarzS, AschoffA, Keller E, Hacke W: Moderate hypothermia and brain temperature in patients with severe middle cerebral artery infarction. Acta Neurochir Suppl 1998; 71: 131-134.

7. Verlooy J, Heytens L, Veeckmans G, Selosse P: Intracerebral temperature monitoring in severely head injured patients. Acta Neurochir (Wien) 1995; 134: 76-78.

8. Wijdicks EF, St Louis E: Clinical profiles predictive of outcome in pontine hemorrhage. Neurology 1997; 49: 1342-1346.

9. Yanamoto H, Nagata I, Niitsu Y, Zhang Z, Xue JH, Sakai N, Kikuchi H: Prolonged mild hypothermia therapy protects the brain against permanent focal ischemia. Stroke 2001; 32: 232-239.

10. Al-Senani FM, Graffagnino C, Grotta JC et al.: A prospective, multicenter pilot study to evaluate the feasibility and safety of using the CoolGard System and Icy catheter following cardiac arrest. Resuscitation 2004; 62: $143-150$.

11. Diringer $M N$ : Treatment of fever in the neurologic intensive care unit with a catheter-based heat exchange system. Crit Care Med 2004; 32: 559-564.

12. Hoedemaekers CW, EzzahtiM, Gerritsen A, van der Hoeven JG: Comparison of cooling methods to induce and maintain normo- and hypothermia in intensive care unit patients: a prospective intervention study. Crit Care 2007; 11: R91.

13. Beer R, LacknerP, Pfausler B, Schmutzhard E: Nosocomial ventriculitis and meningitis in neurocritical care patients. J Neurol 2008; 255: 1617-1624. doi: 10.1007/s00415-008-0059-8.

14. Keller E, Imhof HG, Gasser S, Terzic A, Yonekawa Y: Endovascular cooling with heat exchange catheters: a new method to induce and maintain hypothermia. Intensive Care Med 2003; 29: 939-943.

15. Schmutzhard E, Engelhardt $K$, Beer R et al.: Safety and efficacy of a novel intravascular cooling device to control body temperature in neurologic intensive care patients: a prospective pilot study. Crit Care Med 2002; 30: $2481-2488$.

\section{Corresponding author:}

Ozlem Korkmaz Dilmen, MD, DESA

Staff Anesthesiologist, Department

of Anesthesiology \& Intensive Care

Cerrahpasa, School of Medicine University of Istanbul

34098, Cerrahpasa, Istanbul, Turkey

Tel. +902124143000-21248

Fax: +902124143302

e-mail:korkmazdilmen@gmail.com 